\title{
A ventilator with multiple modes for ventilation and air filtration
}

\author{
Facheng Li ${ }^{1}$, Tengfei (Tim) Zhang ${ }^{2,1}$, Shugang Wang ${ }^{1}$ \\ ${ }^{1}$ Dalian University of Technology, Dalian, China \\ ${ }^{2}$ Tianjin University, Tianjin, China
}

\begin{abstract}
In event of haze and fog in some countries, the outdoor air is polluted and cannot be directly drawn into rooms for ventilation. A ventilator with air filtration is required. Because the outdoor particulate concentrations vary greatly with time, adopting the high efficiency particulate air (HEPA) filtration may not be optimal. This investigation proposed a ventilator with multiple modes of ventilation and air filtration. Different efficiency of air filters were installed into the natural and mechanical ventilation passages. The ventilation rate and indoor particle concentrations were modelled by the EnergyPlus and validated with the experimental data. Then the validated model was adopted to evaluate both indoor air quality and ventilation energy consumption in a hypothetical apartment located in five different climatic zones. Performance of the proposed ventilator and the market-available fresh air blower was compared. It was found that both the proposed ventilator and the fresh air blower were able to assure both indoor $\mathrm{CO}_{2}$ and PM2.5 concentrations within the acceptable level. The operating time of the HEPA filtration for the proposed ventilator was approximately $70 \%$ less than that of the fresh air blower and for the operating energy the ventilator was approximately $30 \%$ less.
\end{abstract}

\section{Introduction}

Commonly, ventilation is thought being able to improve indoor air quality. However, this may not be true when the outdoor air is polluted. For example, in event of haze and fog, the fine particles with aerodynamic size less than $2.5 \square \mathrm{m}$ (PM2.5) can penetrate into buildings through various ventilation paths (Zhou et al.2016). Indoor particle filtration has to be carried out to maintain acceptable low particle concentrations.

It is well known that the high efficiency particulate air (HEPA) filter can remove most of the airborne particles. The inferior features of the HEPA filtration are the high flow resistance (Brent et al., 2010) and the associated maintenance or replacement cost (Montgomery et al., 2012). On the other hand, the outdoor PM2.5 concentrations vary greatly with time and location (Yan et al., 2005). The HEPA filtration may be required only on some severely polluted days and in some specific climatic zones. It is not economical to run HEPA filtration for all of the time.

The indoor particle filtration can remove airborne particles but cannot remove gaseous pollutants. Appropriate ventilation is still needed to dilute gaseous pollutants while filtering airborne particles. A recent study (Zhang et al., 2018) revealed that the natural ventilation together with portable air cleaning has the lowest operating expense and is able to lower the indoor airborne particle concentrations within the acceptable level. However, the ventilation rate may occasionally be insufficient. The mechanical ventilation combining with particle filtration has a good capability to satisfy both the ventilation and particle filtration demand, but the running expense is the highest. There is still lack of a ventilator that can respond to the outdoor weather and pollution conditions to provide the exactly demanded ventilation and particle filtration.

To develop the ventilation and air cleaning means, a software program that is able to simulate both indoor air quality and energy consumption is required. The EnergyPlus was recently extended to simulate indoor air quality from the conventional building energy simulation (Chen et al., 2015). The EnergyPlus was validated with an acceptable performance to resolve ventilation rate (Zhang et al., 2013), energy consumption (Zhou et al., 2008), and PM2.5 concentration (Taylor et al., 2014), and also evaluate the ventilation and air cleaning strategies (Zhang et al., 2018).

This investigation proposed a ventilator that is able to naturally and mechanically ventilate a room and provide particle filtration on demand. Performance of the ventilator was modelled by the EnergyPlus software. Accuracy of the modeling was evaluated by the measurement data obtained in a test room utilizing such a ventilator. Then the ventilator was simulated to improve the indoor air quality in a family in five different climatic zones in China. Both the achieved indoor air quality and the required operating energy of the ventilator were solved. The market-available fresh air blower with the EPA filtration was adopted as a reference case to evaluate the proposed ventilator.

\section{Methods}

\section{Proposed ventilator}

The proposed ventilator contains the mechanicallydriven flow passage and the naturally-driven flow passage, as shown in Figure 1(a). Within the mechanical flow passage, there are a medium-efficiency particulate air filter, a HEPA filter, and a centrifugal fan. A primary 
filter and a regulating baffle were installed in the natural flow passage. In addition, there are three motor-driven sliding movers to control the opening or closing of the bypass port between the both flow passages, the indoor recirculated air inlet opening, and the port for the incoming natural wind without filtration (not shown in Figure 1(a)).

The flow rate regulation baffle is rotatable with the pivot in the middle to the upper part of the baffle. Hence the torque by the gravitation is counter-clockwise, based on Figure 1(b). Due to hiding of the upper baffle inside the natural flow passage, the wind-driven torque is clockwise. Hence, both torques compromise between to stabilize the incoming airflow rate into the room by wind. For example, when encountering a mild wind, the gravity keeps the baffle close to the vertical position, so the flow passage tends to be large. However, when encountering a strong wind, the baffle stays close to the horizontal, which nearly shuts the flow passage.

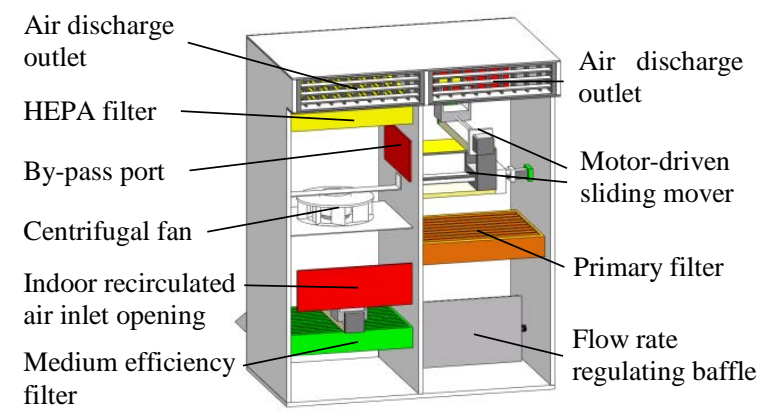

(a)

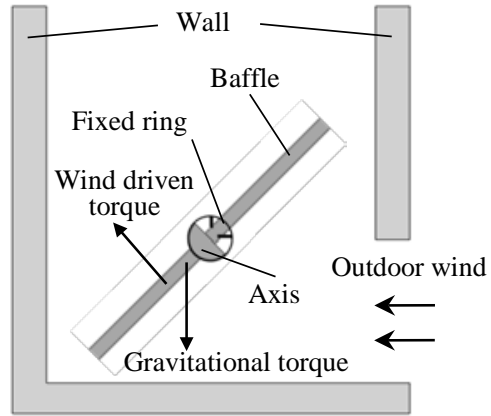

(b)

Figure 1: Schematics of the ventilator: (a) basic components and structure; (b) principles of the winddriven flow rate regulation.

The ventilator contains a total of five operating modes and the operating modes were switched by the motordriven sliding mover. Figure 2 presents the five different operating modes. The HEPA filtration mode applies to the medium to severe pollution conditions. Both the medium-efficiency and HEPA filtration operate in series driven by the centrifugal fan, as shown in Figure 2(a). The pure medium-efficiency filtration applies to the light pollution condition with mild wind. The outdoor air driven by the fan passes the medium-efficiency filter and then through the by-pass port into the other flow passage and finally into the room, as shown in Figure 2 (b).
Because the much larger flow resistance of the HEPA filter than the flow passage in the right, there is nearly no flow passing the HEPA filter. Figure 2(c) shows the recirculated indoor air filtration, which may be applied when a quick removal of indoor airborne particles is required. The fan extracts the indoor air from the indoor recirculated air inlet opening into the flow passage and then passes the HEPA filter. Figure 2(d) shows the natural introduction of the outdoor air without filtration, which can only be used when there is no outdoor air pollution, and the external driven force, such as wind, is available. In case the outdoor air is slightly polluted and the outdoor wind is strong enough, the natural ventilation with filtration mode can be run, as shown in Figure 2(e). In the left flow passage, some of the outdoor air is pressed into the room by passing the mediumefficiency filter and the indoor recirculated air inlet opening into the room if it is opened. In the right passage, the outdoor air passes the regulating baffle and the primary filter and finally into the room.

The constructed ventilator based on the above scheme was installed below the window in a test room as shown in Figure 3. The dimensions of the ventilator were 0.61 $\mathrm{m} \times 0.35 \mathrm{~m} \times 0.81 \mathrm{~m}$. The test room had dimensions of 4.8 $\mathrm{m} \times 3.3 \mathrm{~m} \times 2.7 \mathrm{~m}$, and thus the floor area was $15.84 \mathrm{~m}^{2}$ and the room's volume was $42.8 \mathrm{~m}^{3}$. The test room was located in Dalian, a coastal city in northeastern China.

The performance of the ventilator in terms of ventilation flow rate, fan power consumption, particle filtration efficiency, was measured. The ventilation flow rate was measured by an air capture hood together with the micro-manometer (type: 8380; TSI, USA). The measurement resolution was $1 \mathrm{~m}^{3} / \mathrm{h}$ and the accuracy was within $\pm 3 \%$ of the reading value. The fan power consumption rate was measured by a digital power meter (type: PM9805; NAPUI, China). The measurement resolution was $0.1 \mathrm{~W}$ and the accuracy was within $\pm 0.4 \%$ of the reading data. The particle filtration efficiency was evaluated by the single pass concentration reduction after the filter. The instrument to record particle concentration was the aerosol monitor (type: 8533; TSI, USA). The resolution of the measured particle concentration was $1 \mu \mathrm{g} / \mathrm{m}^{3}$, and the accuracy was within $\pm 0.1 \%$ of the reading concentration.

To measure the resistance versus flow rate for the natural ventilation with and without filtration, the air intakes of the both natural and mechanical flow passages were attached to a simplified wind tunnel, respectively. The flow rate was varied by changing the rotational speed of the fan in the wind tunnel. The pressure difference between the air intake and the air discharge outlet was measured by a micro-manometer (type: 8715 ; TSI, USA) The resolution of the test instrument was $0.001 \mathrm{~Pa}$, and the accuracy was within $\pm 2 \%$ of the reading pressure difference. 


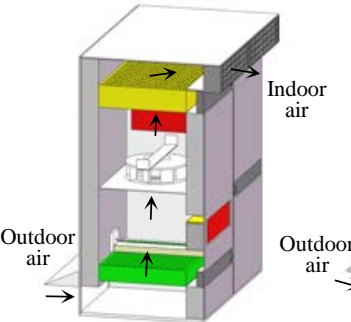

(a)

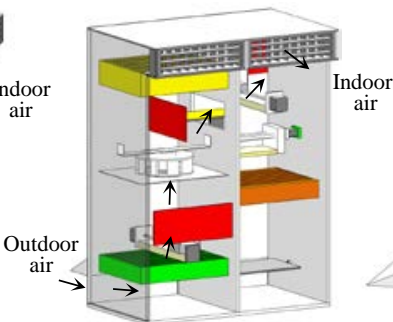

(b)

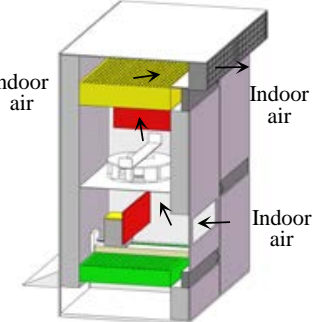

(c)

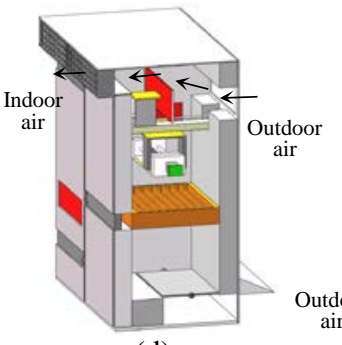

(d)

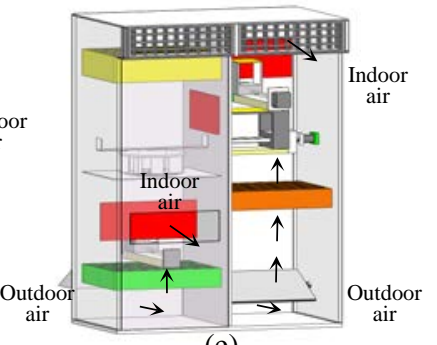

(e)

Figure 2: Schematics of five different operating modes of the ventilator and the airflow motion therein: (a) HEPA filtration, (b) middle-efficiency filtration, (c) recirculated indoor air filtration, (d) natural ventilation without filtration, (e) natural ventilation with filtration.

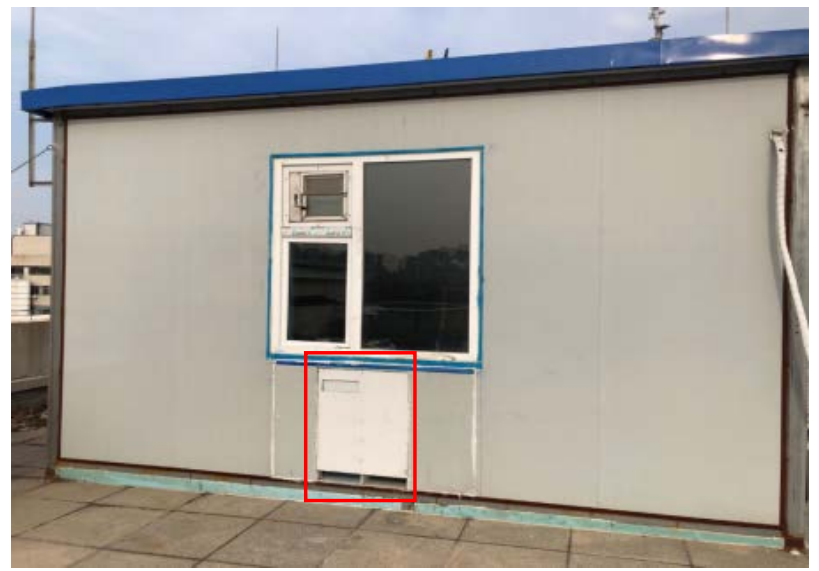

Figure 3: A ventilator installed below the window of a test room (the southern view).

\section{Numerical simulation modeling}

The ventilator can sustain natural ventilation. The airflow rate driven by natural ventilation with and without filtration can be calculated as:

$$
Q=C_{Q}(\Delta P)^{n}
$$

where $Q$ is the volumetric flow rate $\left(\mathrm{m}^{3} / \mathrm{s}\right), C_{Q}$ is the flow coefficient, $\Delta P$ is the pressure difference $(\mathrm{Pa})$, and $n$ is the exponent.

The particle concentration in a room can be calculated according to the mass balance principle as:

$$
\begin{aligned}
& V \frac{\mathrm{d} C_{i}}{\mathrm{~d} t}=E+\sum_{j} k_{j} F_{j \rightarrow i} C_{j}-\sum_{j} k_{j} F_{i \rightarrow j} C_{i}-\left(k_{g} V+C A D R\right) \times C_{i^{-}} \\
& F_{V} \eta C_{\text {out }}
\end{aligned}
$$

where $V$ is the room's volume, $C$ is the PM2.5 concentration, $t$ is time, $E$ is the PM2.5 source release rate, $i$ and $j$ are room indices, $k_{j}$ is the particulate penetration ratio from zone $j$ to zone $i, F$ is the airflow rate between zones, $k_{\mathrm{g}}$ is the gravitational settling rate, CADR is the clean air delivery rate of an air cleaner, $F_{\mathrm{v}}$ is airflow rate of the ventilator, $\eta$ is particle filtration efficiency of the ventilator, and $C_{\text {out }}$ is the outdoor PM2.5 concentration.

The proposed ventilator was assumed to run in an apartment, as shown in Figure 4. A total of four persons resided in this apartment. The living room was occupied by the whole family from 18:00 to 22:00 on the work days, and 11:00 to 22:00 on the weekends. From 22:00 to 7:00, room 1 was present by two persons, while rooms
2 and 3 were present by a single person, respectively.

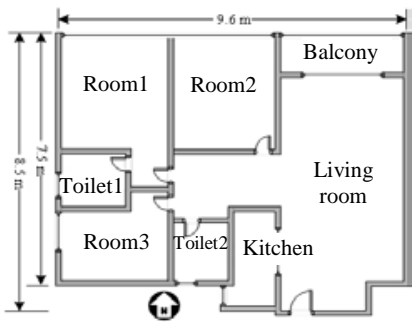

(a)

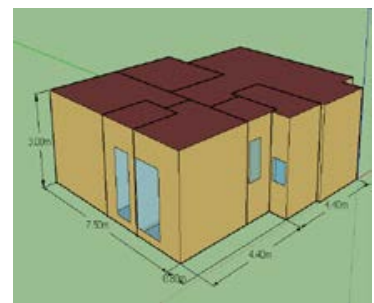

(b)
Figure 4: A typical apartment to evaluate performance of the proposed ventilator: (a) floor map of the apartment, (b) geometric model created in the EnergyPlus software.

Each room, including the living room and rooms 1 to 3, was assumed to be installed with either a ventilator proposed in this investigation or a market-available fresh air blower with the pure HEPA filtration. A total of three ventilation types were numerically investigated, i.e., the natural ventilation without using the ventilator or the fresh air blower, the ventilation by the proposed ventilators, and the ventilation by the fresh air blowers together with HEPA filtration and indoor air cleaners. The first ventilation type was investigated to evaluate whether the natural ventilation without particle filtration could assure indoor ventilation and air quality. The last ventilation type was adopted to compare performance between the proposed ventilator and the marketavailable fresh air blower. Because the market-available fresh air blower with the HEPA filtration might not be sufficient to control the indoor particle concentrations, an indoor air cleaner was added to each room. In the first ventilation type, the windows were allowed be opened when the outdoor temperature ranged from 16 to $28{ }^{\circ} \mathrm{C}$ and the outdoor PM2.5 concentration was below 35 $\mu \mathrm{g} / \mathrm{m}^{3}$. The sequence to switch the operation mode of the ventilator was: the natural ventilation without filtration (as shown in Figure 2(d)) and no window was opened, the natural ventilation with filtration (Figure 2(e)), the mechanical ventilation with the medium-efficiency filtration (Figure 2(b)), the mechanical ventilation with the HEPA filtration (Figure 2(a)), and the recirculated indoor air filtration (Figure 2(c)). That is, if a prior mode can satisfy both the $\mathrm{CO}_{2}$ and indoor particle concentration requirements, no posterior mode will be utilized to save energy. When adopting the ventilator, 
the indoor $\mathrm{CO}_{2}$ concentration was controlled less than $1000 \mathrm{ppm}$ and the PM2.5 concentration below $35 \mu \mathrm{g} / \mathrm{m}^{3}$. And the same $\mathrm{CO}_{2}$ and PM2.5 concentrations were maintained by the last ventilation type. However, the window was allowed to open and the blower and cleaner were shut if the outdoor temperature was between 16 and $28{ }^{\circ} \mathrm{C}$ and the outdoor PM2.5 concentration was below $35 \mu \mathrm{g} / \mathrm{m}^{3}$. The mechanical ventilation rate of the ventilator and the fresh air blower were the same as 30 $\mathrm{m}^{3} / \mathrm{h}$ per person. The maximum CADR of the indoor air cleaner was $600 \mathrm{~m}^{3} / \mathrm{h}$, just as the CADR for the recirculated air filtration of the ventilator. The HEPA filtration efficiency and the operating energy consumption rate between the fresh air blower and the HEPA filtration mode of the ventilator were assumed same.

Each person was supposed to generate $\mathrm{CO}_{2}$ at a rate of $18 \mathrm{l} / \mathrm{h}$. The outdoor $\mathrm{CO}_{2}$ concentration was fixed to 400 ppm. The outdoor PM2.5 concentration in the simulation was set as the recorded hour-average values by the meteorological bureau of the considered city in 2016 . When the windows were closed, approximately $80 \%$ of the outdoor particles could penetrate into rooms through infiltration. No particles were intercepted if the windows were opened. The particle settling rate due to gravity was assumed being equivalent to an air change rate of 0.09 air changes per hour (ACHs). Cooking in the kitchen also contributed to release of the PM2.5. The range hood in kitchen and exhausted fans in both toilets also helped ventilation. The appliances and airconditioners were also run as the prescribed schemes. The detailed settings were the same as those documented in Zhang et al. (2018). Due to the limited space, these settings were not repeated at here.

The apartment adopting the three ventilation types was assumed to locate in five different cities in China. Each city corresponds to a different climatic zone. These cities are, Shenyang in the severely cold zone, Tianjin in the cold zone, Chengdu in the hot summer and cold winter

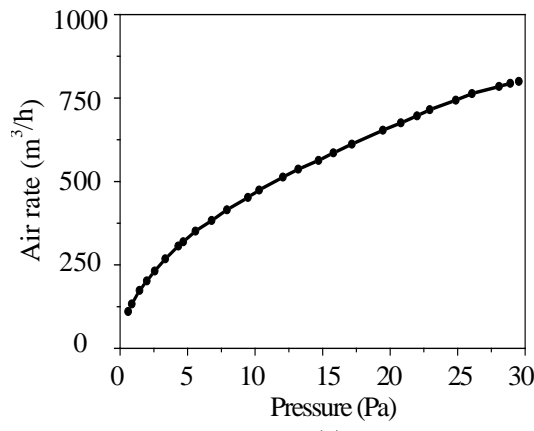

(a)

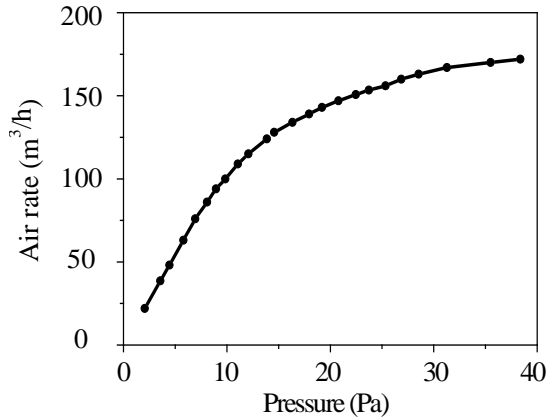

(b)

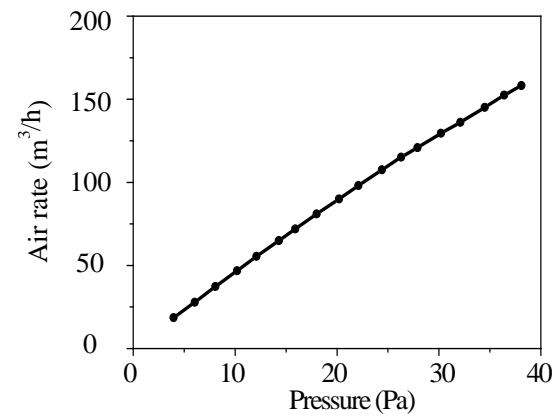

(c)

Figure 5: Volumetric airflow rate versus pressure difference across the ventilator: (a) natural ventilation without filtration, (b) natural ventilation with filtration in the natural flow passage, (c) natural ventilation with filtration in the mechanical flow passage.

Table 1 presents the measured consumption power and the filtration efficiency of different operation modes under the designed ventilation rates. The natural filtration corresponded to a pressure difference of 7.9 $\mathrm{Pa}$ across the ventilator and $0.715 \mathrm{~Pa}$ for the natural zone, Shenzhen in the hot summer and warm winter zone, and Kunming in the mild climate zone. Because he same apartment was investigated in different cities, insulation, air tightness and the local climatic and pollution conditions. The building insulation and air ightness were set in agreement with the national regulations prescribed in the local cities.

The indoor air quality in terms of the $\mathrm{CO}_{2}$ and PM2.5 concentrations for three different ventilation types and the energy consumption of both the proposed ventilator and the fresh air blower were evaluated.

\section{Results}

\section{Model validation}

As shown in Eq. (1), both the flow coefficient $\left(C_{Q}\right)$ and the exponent $(n)$ should be specified when modeling the natural ventilation rates of the ventilator. Figure 5 presents the measured volumetric airflow rates versus the pressure difference between the air intake and the air discharge outlet of the ventilator. The quadratic profile was presented for the natural ventilation without filtration, as shown in Figure 5(a). From the curve-fitting, $C_{Q}=0.0478$ and $n=0.511$ were obtained and then specified into the modeling. Figure 5(b) shows the airflow rate versus the pressure for the natural ventilation passage. The linear profile was presented due to the primary filter when the pressure was less than 10 $\mathrm{Pa}$. Once the pressure was greater than $10 \mathrm{~Pa}$, the flow rate regulating baffle rotated and tended to approach a maximum value. However, because of the mediumefficiency filter in the mechanical flow passage, only the linear profile was obtained as shown in Figure 5(c). Combining Figure 5(b) and 5(c), $C_{Q}=0.0071$ and $n=0.803$ were obtained and specified into the modeling. The settings to calculate the infiltration/exfiltration rate of the test room were the same as those documented in Zhang et al. (2018). ventilation without filtration. The mechanically-driven ventilation rates and PM2.5 filtration efficiency were specified as the known information for modeling.

Figure 6 presents the air change rates versus time on a day in the transitional season for the natural ventilation 
without filtration mode. The wind speed and direction were measured by a portable weather station on the roof of the test room. The southern prevailing wind was switched to the northern prevailing wind since the afternoon. Generally, the ventilation rate proportionally changed with the wind speed. This was because the test room was isolated on the roof of a building. The highest air change rate occurred at 2:00 am and the lowest rate at 19:40. The numerically solved air change rate agreed well with the measurement by the decayed $\mathrm{SF}_{6}$ concentrations.

Table 1: The measured airflow rate, power rate, and PM2.5 filtration efficiency of the ventilator.

\begin{tabular}{|c|c|c|c|c|}
\hline Mode & $\begin{array}{c}\text { Airflow } \\
\text { rate } \\
\left(\mathrm{m}^{3} / \mathbf{h}\right)\end{array}$ & $\begin{array}{l}\text { Power } \\
\text { rate } \\
(\mathrm{W})\end{array}$ & $\begin{array}{l}\text { Filtration } \\
\text { efficiency }\end{array}$ & $\begin{array}{c}\text { PM2.5 } \\
\text { concentratio } \\
\text { n before } \\
\text { filtration } \\
\left(\mu \mathrm{g} / \mathbf{m}^{3}\right)\end{array}$ \\
\hline \multirow{3}{*}{$\begin{array}{c}\text { Mechanically } \\
\text { driven HEPA } \\
\text { filtration }\end{array}$} & 30 & 14.7 & \multirow{3}{*}{$99.8 \%$} & \multirow{3}{*}{157.8} \\
\hline & 60 & 17.7 & & \\
\hline & 120 & 24.1 & & \\
\hline \multirow{3}{*}{$\begin{array}{l}\text { Mechanically } \\
\text { driven } \\
\text { medium } \\
\text { filtration }\end{array}$} & 30 & 14.0 & \multirow{3}{*}{$64.8 \%$} & \multirow{3}{*}{81.8} \\
\hline & 60 & 15.3 & & \\
\hline & 120 & 18.2 & & \\
\hline \multirow{3}{*}{$\begin{array}{l}\text { Recirculated } \\
\text { indoor air } \\
\text { filtration }\end{array}$} & 30 & 14.4 & \multirow{3}{*}{$99.6 \%$} & \multirow{3}{*}{154.1} \\
\hline & 60 & 16.6 & & \\
\hline & 120 & 22.8 & & \\
\hline $\begin{array}{c}\text { Natural } \\
\text { ventilation } \\
\text { with } \\
\text { filtration } \\
\end{array}$ & 120 & 0 & $40 \%$ & 49.6 \\
\hline $\begin{array}{c}\text { Natural } \\
\text { ventilation } \\
\text { without } \\
\text { filtration }\end{array}$ & 120 & 0 & 0 & - \\
\hline
\end{tabular}

Figure 7 presents comparison of the solved and measured air change rates for the natural ventilation with filtration mode. The air change rate profiles also somewhat followed the wind speed profile but not very well. This was because the filter minimized the wind pressure interruption. Again, the numerical modeling provided the ventilation rate in a good agreement with the measurement.

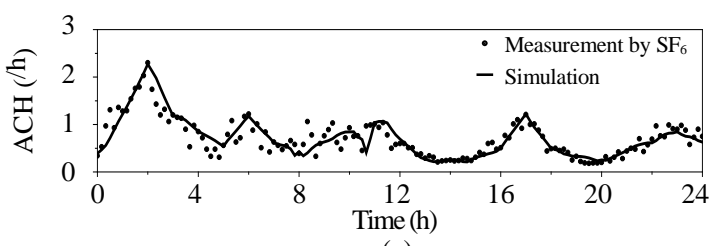

(a)

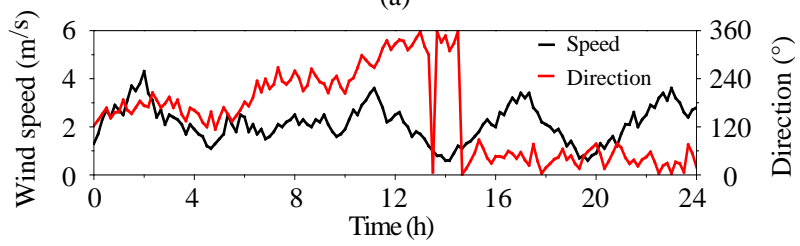

(b)

Figure 6: Comparison of the simulated and measured ventilation rates for the natural ventilation without filtration: (a) air change rate versus time, (b) outdoor wind speed and direction.
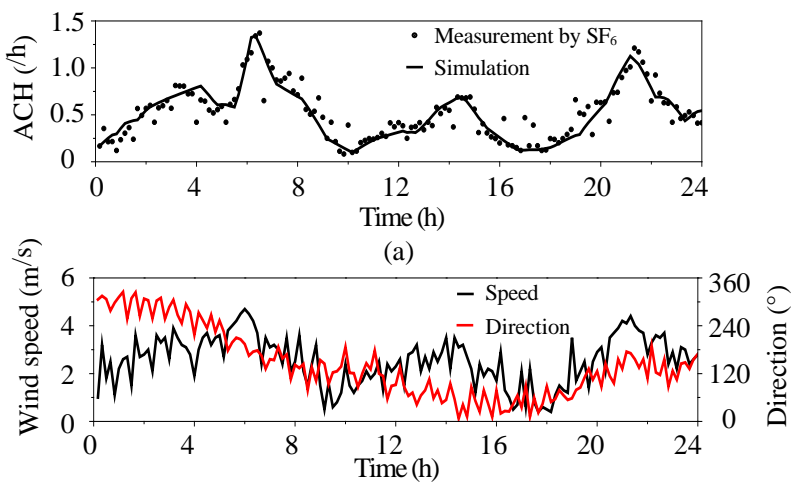

(b)

Figure 7: Comparison of the simulated and measured ventilation rates for the natural ventilation with filtration: (a) air change rate versus time, (b) outdoor wind speed and direction.

Figure 8 presents comparison of the simulated and measured indoor PM2.5 concentrations for different operating modes of the ventilator on three different days in May and June. The natural ventilation with filtration mode was adopted when the outdoor PM2.5 concentration was below $60 \mu \mathrm{g} / \mathrm{m}^{3}$. The mechanically driven medium-efficiency filtration was used when the outdoor PM2.5 concentration ranged from 60 to 90 $\mu \mathrm{g} / \mathrm{m}^{3}$. The HEPA filtration was implemented when the outdoor PM2.5 concentration ranged from 90 to 180 $\mu \mathrm{g} / \mathrm{m}^{3}$. Regardless of the ventilation mode, the simulation obtained similar indoor PM2.5 concentrations as the measurement.

The above comparison of the ventilation rate and indoor PM2.5 concentration when adopting various filtration modes revealed that the numerical model was able to provide results in good agreement with the measurement. This validated the reliability of the adopted numerical modeling. 


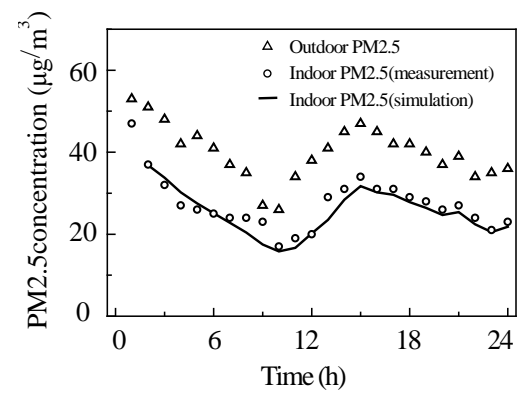

(a)

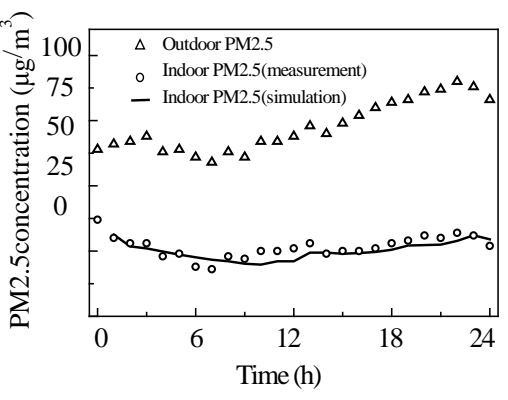

(b)

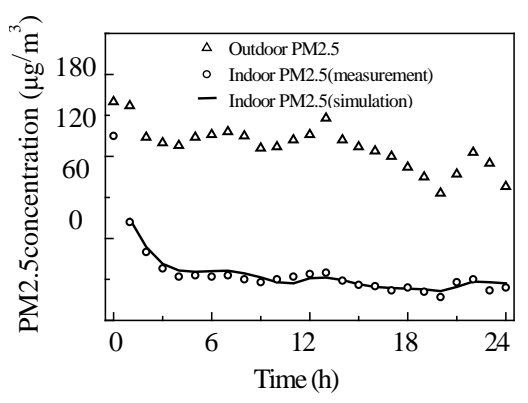

(c)

Figure 8: Comparison of the simulated and measured indoor PM2.5 concentrations: (a) natural filtration mode, (b) mechanically driven medium-efficiency filtration, (c) HEPA filtration.

\section{Simulated performance in the apartment in five cities}

Table 2 lists percentages of the total occupied time with the indoor hour-average $\mathrm{CO}_{2}$ concentration exceeding $1000 \mathrm{ppm}$. It shows that when adopting the natural ventilation both living and bed rooms had a high time ratio with the $\mathrm{CO}_{2}$ concentration greater than $1000 \mathrm{ppm}$. The time ratios in bedrooms were higher than those in the living room because of longer residence time in the bedrooms. The time ratios vary in different cities. In general, the time ratios in Kunming were slightly lower, due to the mild climate conditions, while the time ratios in Tianjin was the highest due to the climate and airtightness of the buildings in northern China. However, after adopting the ventilator or the fresh air blower, neither had $\mathrm{CO}_{2}$ concentration exceeding $1000 \mathrm{ppm}$. This implies that the mechanically-driven devices are required if the $\mathrm{CO}_{2}$ concentration less than 1000 ppm must be guaranteed in all of the occupied time.

Table 2: Simulated percentages of the total occupied time (\%) with the indoor hour-average $\mathrm{CO}_{2}$ concentration exceeding 1000 ppm.

\begin{tabular}{|c|c|c|c|c|c|c|}
\hline Case & Room & $\begin{array}{l}\text { Shen } \\
\text { yang }\end{array}$ & $\begin{array}{c}\text { Tian } \\
\text { jin }\end{array}$ & $\begin{array}{c}\text { Chen } \\
\text { gdu }\end{array}$ & $\begin{array}{l}\text { Shen } \\
\text { zhen }\end{array}$ & $\begin{array}{l}\text { Kun } \\
\text { ming }\end{array}$ \\
\hline \multirow{4}{*}{$\begin{array}{c}\text { Natural } \\
\text { ventilat } \\
\text { ion }\end{array}$} & $\begin{array}{c}\text { Living } \\
\text { room }\end{array}$ & 40.3 & 52.4 & 49.7 & 42.5 & 22.3 \\
\hline & $\begin{array}{c}\text { Room } \\
1\end{array}$ & 77.7 & 81.2 & 77.9 & 64.0 & 67.5 \\
\hline & $\begin{array}{c}\text { Room } \\
2\end{array}$ & 76.3 & 80.7 & 77.1 & 60.0 & 65.2 \\
\hline & $\begin{array}{c}\text { Room } \\
3\end{array}$ & 76.6 & 81.0 & 77.3 & 62.1 & 66.4 \\
\hline \multirow{4}{*}{$\begin{array}{l}\text { Ventila } \\
\text { tor/ } \\
\text { Fresh } \\
\text { air } \\
\text { blower }\end{array}$} & $\begin{array}{c}\text { Living } \\
\text { room }\end{array}$ & 0 & 0 & 0 & 0 & 0 \\
\hline & $\begin{array}{c}\text { Room } \\
1\end{array}$ & 0 & 0 & 0 & 0 & 0 \\
\hline & $\begin{array}{c}\text { Room } \\
2\end{array}$ & 0 & 0 & 0 & 0 & 0 \\
\hline & $\begin{array}{c}\text { Room } \\
3\end{array}$ & 0 & 0 & 0 & 0 & 0 \\
\hline
\end{tabular}

Table 3 presents percentages of the total occupied time with the indoor hour-average PM2.5 concentration greater than $35 \mu \mathrm{g} / \mathrm{m}^{3}$. The natural ventilation without air cleaning could not assure the indoor PM2.5 concentration below $35 \mu \mathrm{g} / \mathrm{m}^{3}$. The time ratios in Shenzhen and Kunming were lower due to better outdoor conditions in these two cities. If less than $10 \%$ of time ratio with the indoor PM2.5 concentration greater than $35 \mu \mathrm{g} / \mathrm{m}^{3}$ was allowed, no particle filtration was required in Shenzhen and Kunming. However, the remaining cities had higher time ratios of the indoor PM2.5 concentration and thus required airborne particle removal. For contrast, both the proposed ventilator and fresh air blower were able to get the indoor PM2.5 concentration within the set acceptable level.

Table 3: Simulated percentages of the total occupied time (\%) with the indoor hour-average PM2.5 concentration greater than $35 \mu \mathrm{g} / \mathrm{m}^{3}$.

\begin{tabular}{|c|c|c|c|c|c|c|}
\hline Case & Room & $\begin{array}{l}\text { Shen } \\
\text { yang }\end{array}$ & $\begin{array}{c}\text { Tian } \\
\text { jin }\end{array}$ & $\begin{array}{c}\text { Chen } \\
\text { gdu }\end{array}$ & $\begin{array}{l}\text { Shen } \\
\text { zhen }\end{array}$ & $\begin{array}{l}\text { Kun } \\
\text { ming }\end{array}$ \\
\hline \multirow{4}{*}{$\begin{array}{c}\text { Natural } \\
\text { ventilat } \\
\text { ion }\end{array}$} & $\begin{array}{l}\text { Living } \\
\text { room }\end{array}$ & 32.1 & 45.5 & 40.2 & 6.1 & 2.7 \\
\hline & $\begin{array}{c}\text { Room } \\
1\end{array}$ & 27.7 & 31.5 & 28.7 & 1.6 & 1.2 \\
\hline & $\begin{array}{c}\text { Room } \\
2\end{array}$ & 29.0 & 31.8 & 28.6 & 2.8 & 1.3 \\
\hline & $\begin{array}{c}\text { Room } \\
3 \\
\end{array}$ & 33.2 & 31.5 & 28.8 & 2.6 & 1.2 \\
\hline \multirow{4}{*}{$\begin{array}{l}\text { Ventila } \\
\text { tor/ } \\
\text { Fresh } \\
\text { air } \\
\text { blower }\end{array}$} & $\begin{array}{c}\text { Living } \\
\text { room }\end{array}$ & 0 & 0 & 0 & 0 & 0 \\
\hline & $\begin{array}{c}\text { Room } \\
1\end{array}$ & 0 & 0 & 0 & 0 & 0 \\
\hline & $\begin{array}{c}\text { Room } \\
2\end{array}$ & 0 & 0 & 0 & 0 & 0 \\
\hline & $\begin{array}{c}\text { Room } \\
3\end{array}$ & 0 & 0 & 0 & 0 & 0 \\
\hline
\end{tabular}

Figure 9 presents the time ratio of each operating mode for both the proposed ventilator and the fresh air blower in five cities. The total occupation time in the apartment was 5473 hours, based on which the absolute utilization time of each operating mode could be calculated. The natural ventilation with and without filtration could be used relatively longer in both Shenyang and Shenzhen, because of the higher outdoor wind speeds in these two cities than the remaining cities. In Kunming, although the natural ventilation without filtration could be utilized as long as in Shenzhen, the natural ventilation without filtration using the ventilator could be used in a shorter time ratio. This was because the outdoor wind speed in Kunming was lower than in Shenzhen, the small opening for natural ventilation in the proposed ventilator limited 
the ventilation rate. A comparison between the proposed ventilator and the fresh air blower showed approximately $70 \%$ of the time ratio to operate the HEPA filtration could be saved after adopting the proposed ventilator. The mechanical medium filtration was sufficient to remove the airborne PM2.5 in both Shenzhen and Kunming.

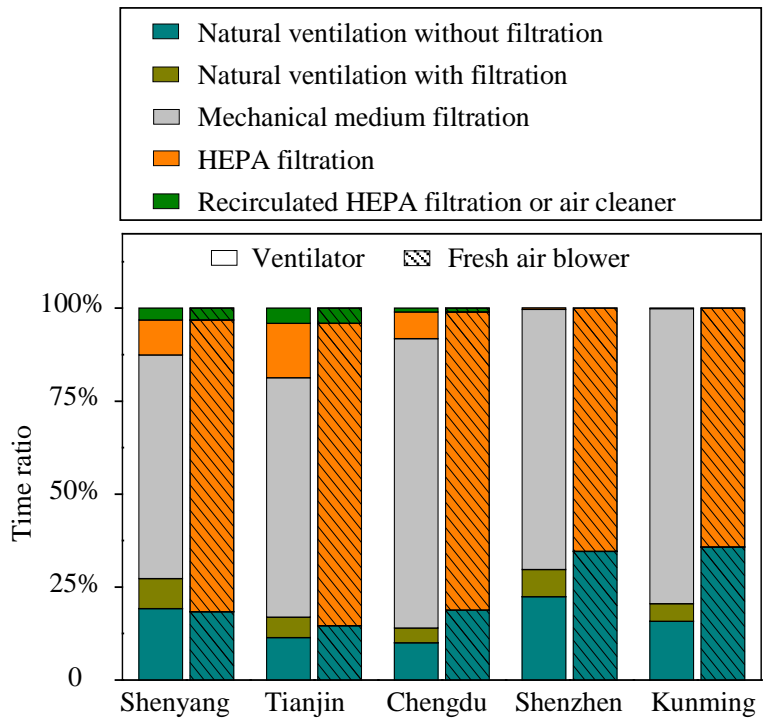

Figure 9: Time ratios of each operating mode for both the ventilator and the fresh air blower in five cities.

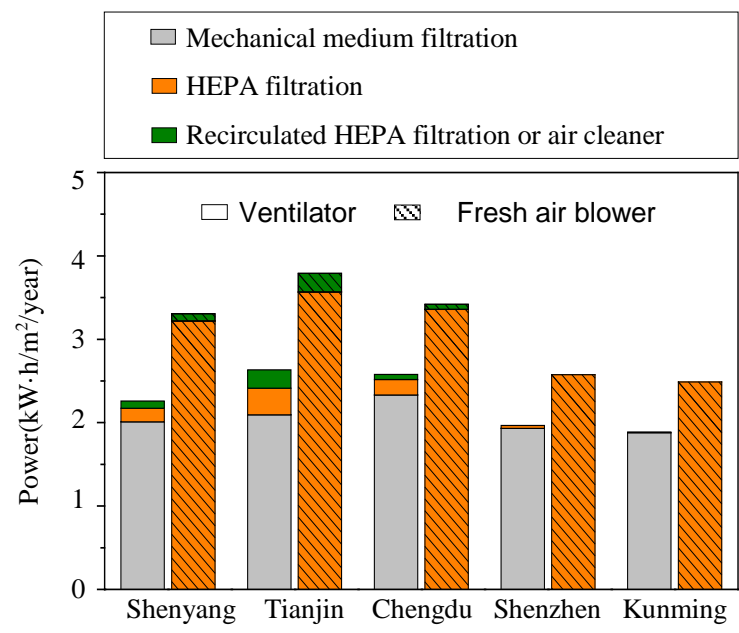

Figure 10: Operating energy of both the ventilator and fresh air blower averaged to per unit floor area in five cities.

Figure 10 presents the required operating energy averaged to per unit floor area for both the ventilator and the fresh air blower. The operating energy for ventilation in Tianjin, Chengdu, and Shenyang was higher than the remaining two cities. Most of the operating energy for the ventilator was consumed by the mechanical medium filtration due to the longest operating time. As compared with the fresh air blower, the proposed ventilator required approximately $70 \%$ of the operating energy to maintain the same indoor air quality.

\section{Discussion}

This investigation revealed that the operating time of each mode of the proposed ventilator was highly subject to the climatic conditions, the outdoor PM2.5 concentration, number of indoor occupants, and the floor area of the rooms. The operating time of the mechanical mode was affected by the natural ventilation potential of the considered apartment. It is known that the natural ventilation potential is dependent on climatic zone, terrain, surrounding building shielding, floor height, building orientation, apartment configuration, etc. This paper presented application of the ventilator only in a specific apartment configuration. It should be aware that the operating time and energy consumption of the ventilator may vary with the above impact factors.

The operation of the HEPA filtration was in event of severe outdoor pollution, during which the outdoor wind was relatively weak. Because of the fixed ventilation rate during the HEPA filtration, the operating time of the HEPA filtration was mainly determined by the outdoor PM2.5 concentration and the number of indoor occupants, while the apartment configuration had minimal effect.

Switching of the operating mode was assumed suitably according to the $\mathrm{CO}_{2}$ and PM2.5 concentrations. However, in reality this requires a smart control system based on the monitored $\mathrm{CO}_{2}$ and PM2.5 concentrations. The authors recently constructed a ventilator prototype that could switch mode automatically. Such a ventilator had been preliminarily tested with a good capability to control indoor $\mathrm{CO}_{2}$ and PM2.5 concentrations. Our further investigation will provide measurement data to validate the modeling proposed in this investigation.

\section{Conclusion}

This paper proposed a ventilator containing multiple operating modes that could respond to various climatic and pollution conditions. Performance of the ventilator was modelled by the EnergyPlus software and the modeling was validated by the measurement data obtained in a test room. Then the validated modeling was adopted to evaluate both indoor air quality and ventilation energy consumption in a hypothetical apartment located in five different climatic zones. Performance of the proposed ventilator and the marketavailable fresh air blower was compared. It was found both the proposed ventilator and the fresh air blower were able to assure both indoor $\mathrm{CO}_{2}$ and PM2.5 concentrations within the acceptable level in all of the occupied time. As compared with the fresh air blower, the proposed ventilator had approximately $70 \%$ less of the operating time of the HEPA filtration, while providing the same indoor air quality. In Shenzhen and Kunming, the mechanically driven medium-efficiency filtration was sufficient to get the airborne PM2.5 concentration into the acceptable level. The proposed ventilator saved approximately $30 \%$ of the operating energy as compared with the fresh air blower. 


\section{Acknowledgement}

This work was supported by the National Key Basic Research and Development Program (Grant No.: 2016YFC0700500) and the Natural Science Foundation of China (Grant No.: 51622804).

\section{References}

Zhou, Z., Liu, Y., Yuan, J., Zuo, J., Chen, G., and Xu, L. (2016). Indoor pm2.5 concentrations in residential buildings during a severely polluted winter: a case study in Tianjin, China. Renewable and Sustainable Energy Reviews, 64, 372-381.

Brent, S., Atila, N., and Siegel, J. (2010). The effects of filtration on pressure drop and energy consumption in residential HVAC systems (rp-1299). HVAC\&R Research, 16(3), 273-294.

Montgomery, J. F., Green, S.I., Rogak, S.N., Bartlett, K. (2012). Predicting the energy use and operation cost of HVAC air filters. Energy and Buildings, 47, 643650.

Yan, D., Lei, Y., Shi, Y., Zhu, Q., Li, L., and Zhang, Z. (2018). Evolution of the spatiotemporal pattern of pm2.5 concentrations in china - a case study from the beijing-tianjin-hebei region. Atmospheric Environment, 183, 225-233.
Zhang, T., Su, Z., Wang, J., and Wang, S. (2018). Ventilation, indoor particle filtration, and energy consumption of an apartment in northern China. Building and Environment, 143, 280-292.

Chen, Y., Gu, L., and Zhang, J. (2015). Energyplus and champs-multizone co-simulation for energy and indoor air quality analysis. Building Simulation, 8(4), 371-380.

Zhang, R., Lam, K.P., Yao, S.C., and Zhang, Y. (2013). Coupled Energyplus and computational fluid dynamics simulation for natural ventilation. Building and Environment, 68, 100-113.

Zhou, Y.P., Wu, J.Y., Wang, R. Z., Shiochi, S., and Li, Y.M. (2008). Simulation and experimental validation of the variable-refrigerant-volume (VRV) airconditioning system in Energyplus. Energy and Buildings, 40(6), 1041-1047.

Taylor, J., Shrubsole, C., Biddulph, P., Jones, B., Das, P., Davies, M. (2014). Simulation of pollution transport in buildings: The importance of taking into account dynamic thermal effects. Building Services Engineering Research and Technology. 35(6), 682690. 